\title{
Correction to: One university's story on teacher preparation in elementary mathematics: examining opportunities to learn
}

\section{Casedy A. Thomas ${ }^{1}$ (D)}

Published online: 17 March 2021

(c) Springer Nature B.V. 2021

\section{Correction to: Journal of Mathematics Teacher Education https://doi.org/10.1007/s10857-021-09487-3}

Unfortunately, the acknowledgement section has been missed out in the original publication of the article. The correct version of acknowledgement is provided below.

Acknowledgements This material is based upon work supported by the Spencer Foundation under Grant No. 201600103 and the National Science Foundation under Grant No. DGE 1535024. Any opinions, findings, and conclusions or recommendations expressed in this material are those of the author and do not necessarily reflect the views of the funders.

Publisher's Note Springer Nature remains neutral with regard to jurisdictional claims in published maps and institutional affiliations.

The original article can be found online at https://doi.org/10.1007/s10857-021-09487-3.

Casedy A. Thomas

cathomas14@ua.edu

1 The University of Alabama, 201 Carmichael Hall, Tuscaloosa, AL 35401, USA 